\title{
Study of Stafne's defects in Late Neolithic, Late Roman, Medieval and Modern skeletal samples from Portugal
}

\begin{tabular}{|c|c|}
\hline Journal: & International Journal of Osteoarchaeology \\
\hline Manuscript ID: & OA-10-0061.R1 \\
\hline Wiley - Manuscript type: & Research Article \\
\hline $\begin{array}{r}\text { Date Submitted by the } \\
\text { Author: }\end{array}$ & $\mathrm{n} / \mathrm{a}$ \\
\hline Complete List of Authors: & $\begin{array}{l}\text { Wasterlain, Sofia; University of Coimbra, Department of Life } \\
\text { Sciences } \\
\text { Silva, Ana Maria; University of Coimbra, Department of Life } \\
\text { Sciences }\end{array}$ \\
\hline Keywords: & $\begin{array}{l}\text { Stafne's defect, lingual cortical mandibular defect, bone cyst, } \\
\text { Portugal }\end{array}$ \\
\hline
\end{tabular}

\section{SCHOLARONE ${ }^{\text {m }}$} Manuscripts 
Study of Stafne's defects in Late Neolithic, Late Roman, Medieval and Modern skeletal samples from Portugal

Sofia N. Wasterlain* and Ana Maria Silva

Centro de Investigação em Antropologia e Saúde, Department of Life Sciences, University of Coimbra, 3000-056 Coimbra, Portugal

Number of pages: 24

Number of figures: 10

Number of tables: 5

AbBREViATED TITLE: Stafne's defects in Neolithic, Roman, Medieval and Modern samples

KEY WORDS: Stafne's defect, lingual cortical mandibular defect, bone cyst, Portugal.

*Correspondence to: Sofia N. Wasterlain, Departamento de Ciências da Vida, Apartado 3046, 3001-401 Coimbra, Portugal

Telephone: $351239854105 \quad$ Fax: 351239854129

E-mail: sofiawas@antrop.uc.pt 


\section{AbSTRACT}

Lingual mandibular cortical defects (Stafne's defects) are relatively uncommon in recent as well as past populations, but while this condition is often discussed in clinical reports, they are rarely the subject of anthropological research. In this paper, the prevalence of Stafne's bone defects in skeletal samples from Late Neolithic, Late Roman, Medieval and Modern Portugal is investigated $(\mathrm{N}=704$ complete mandibles and 111 incomplete mandibles). The aims of this paper are threefold: (1) to present and analyse for the first time in Portuguese osteological record prevalence data on Stafne's bone defect, (2) to analyse variations in defect prevalence between skeletal samples from a wide temporal array, and (3) to verify if more tenuous lesions in which resorption of the lingual cortex was not yet extensive had the classic radiographic appearance described by Stafne in order to validate the hypothesis that lesions are present clinically in many more cases than published figures indicate. In all cases, differential diagnosis against other conditions that mimic Stafne's defects, namely odontogenic lesions, cysts and neoplasms, was done. In all samples, the evidence of Stafne's defect occurred in 12 individuals (1.7\%), and males (2.84\%) were more frequently affected than females $(0.61 \%)$. When incomplete mandibles were considered, only one left fragment $(0.90 \%)$ exhibited Stafne's defect. Accurate identification of all examples of Stafne's bone defects in antiquity is thought to represent an important contribution to elucidate which factors may be responsible for this trait's cultural, ecological, temporal, and geographical patterning. 
Edward Stafne (1942) was the first to report the presence of "bone cavities" near the angle of 35 mandibles. Several terms have been used since: Stafne's bone cyst, Stafne's idiopathic bone cavity, idiopathic bone concavity of the mandibular, static bone cyst or cavity, latent bone cyst, mandibular embryonic defect, lingual mandibular bone cavity, lingual mandibular cortical defect, aberrant salivary gland defect, and developmental submandibular gland defect of the mandible. Such bone cavities, concavities or depressions generally appear on the lingual aspect of the mandible. They are commonly located near the molar area or just anterior to the angle of the jaw, often beneath the inferior dental canal but above or involving the lower border (Shafer et al., 1983; Regezi et al., 2000; Soames and Southam, 2005). This location of Stafne's defect has an occurrence of $0.1 \%-0.48 \%$ when diagnosed radiologically, although in some studies where mandibles from cadavers were examined the incidence of the lesion could reach 6.06\% (Philipsen et al., 2002). Anterior lingual type of the lesion is seen seven times less frequently and it is usually located between the lower incisor and the premolar areas, above the insertion of the mylohyoid muscle (Apruzzese and Longoni, 1999; Katz et al., 2001; de Courten et al., 2002; Philipsen et al., 2002; Queiroz et al., 2004). An extremely rare variant is located to the lingual or buccal aspects of the ascending mandibular ramus (Philipsen et al., 2002). Stafne's defect affects predominantly adults, between the fifth and sixth decades of life, and is more common in men than in women (Oikarinen and Julku, 1974; Correll et al., 1980; Philipsen et al., 2002; Quesada-Gómez et al., 2006; Dolanmaz et al., 2009). Sometimes, the anomaly is bilateral (Shafer et al., 1983; Queiroz et al., 2004; Soames and Southam, 2005). The defects are of varying depth and usually vary from 1 to 3 $\mathrm{cm}$ in diameter (radiographically), with the widest portion being parallel to the inferior border of the mandible (Whaites, 2007; Vodanović et al., 2009). An extremely large lesion, reaching up to $9 \mathrm{~cm}$, was reported only once (Buchner et al., 1991). Size does not usually alter with age (Stafne, 1942). 
Stafne's bone cavities are generally detected incidentally on routine oral radiographic examination because they are usually asymptomatic, with the exception of some patients with slight pain and/or swelling in the area (Harvey and Noble, 1968; Apruzzese and Longoni 1999; Quesada-Gómez et al., 2006). Sometimes, a depression may be palpable lingually during the intra-oral examination (Sandy and Williams, 1981). Radiographically, they appear as a round or oval, unilocular, well-circumscribed, corticated, uniform radiolucency (Whaites, 2007). More rarely, the defects may be multilocular (Hayashi et al., 1984). Sometimes the borders are sclerotic or not clearly defined (Apruzzese and Longoni, 1999).

The aetiology and pathogenesis of Stafne's defects has been very problematic, but two of the most popular hypothesis are that they are congenital, or that they develop later through pressure resorption. The first hypothesis, originally proposed by Stafne (1942), suggests that the lingual bone cavity could result from a failure of normal bone deposition in the region formerly occupied by cartilaginous tissue. The major objection to this theory is that these defects have rarely been observed in children and are much more common in the middle aged and elderly (Shafer et al., 1983); therefore, it seems probable that these lesions develop later in life, after ossification of the mandible (Apruzzese and Longoni, 1999). Possible causes are speculative, and most authors accept, though without good evidence, that a hyperplastic/hypertrophic lobe of the salivary glands, exerting pressure upon the cortex of the mandible by the respective gland, leads to focal atrophy or resorption of the bone (Barker, 1988; de Courten et al., 2002; Philipsen et al., 2002). According to this view, the submandibular gland is directly related with the posterior location of the defects, while the sublingual gland is related to the anterior location, and the parotid gland with the variants of the ascending ramus of the mandible (Barker, 1988; Philipsen et al., 2002). Defenders of this aetiology support their argument essentially on the fact that glandular tissue is commonly found within the defect of the patients subjected to sialographies or intervened surgically 
(Drage et al., 2003; Quesada-Gómez et al., 2006). On the other hand, Shibata et al. (1991) reported disappearance of the cavity 26 months after removal of the submandibular gland, which led them to relate the development of the lesion to the pressure exerted by the submandibular gland on the cortical bone. In a minority of cases, however, muscular, fibrous connective tissue, lymphatic, adipose tissues, or blood vessels were also reported related with the cavity. In other cases, the cavity was just empty (Apruzzese and Longoni, 1999). Some authors suggest that the facial artery could be associated with these defects, given that an abnormal vascular pressure could originate necrosis and resorption of the adjacent bone (Ariji et al., 1993). For other authors, the diversity of tissues found in surgical reports could be the result of intermitted gland herniation, regression of the herniated gland or, simply, removal of soft parts adjacent to the lesion (Sandy and Williams, 1981).

Differential diagnosis of Stafne's defects is not usually problematic when it occurs in the posterior region of the mandible. Anterior lingual mandibular salivary gland defects may be, however, more difficult to diagnose. The radiolucencies are generally beneath the root apices or partially superimposed. In some cases, they appear between the roots or in an edentulous area (Apruzzese and Longoni, 1999; de Courten et al., 2002). In such cases, when the location of the cavity is atypical or its appearance differs from the typical (eg, lobulated, incompletely corticated, or multiple), conventional radiographs may be inadequate for recognition of the lesion (Drage et al., 2003; Dolanmaz et al., 2009). Therefore, additional diagnostic techniques, namely dental computerized tomography, computerized tomography, magnetic resonance imaging and sialography, may be needed (Branstetter et al., 1999; Segev et al., 2006; Dolanmaz et al., 2009). Computerized tomography has the great advantage of verifying the peripheral origin of the lesion and the conservation of the lingual cortical, which are essential characteristics for excluding other possible pathologies such as apical or residual cysts, non-inflammatory odontogenic cyst, non-ossifying fibroma, fibrous dysplasia, 
traumatic osseous cyst, central giant cell granuloma, brown tumour of hyperparathyroidism, ameloblastoma, or metastasis from a primary malignant tumour (Ariji et al., 1993; Drage et al., 2003; Segev et al., 2006).

The two main therapeutic options are based on either surgical intervention or a 'wait and see' approach. At present, it is believed that Stafne's disease presents no evolutionary changes, and as such conservatory therapy based on periodic clinical and radiological controls suffices (Quesada-Gómez et al., 2006). However, in atypical cases or when diagnostic doubts persist, surgical intervention and histopathologic analysis is indicated to exclude other pathologic entities (Quesada-Gómez et al., 2006; Araújo et al., 2009).

Since 1942, Stafne's defects have often been reported in clinical literature (Karmiol and Walsh, 1968; Correll et al., 1980; Sandy and Williams, 1981; Hayashi et al., 1984; Apruzzese and Longoni, 1999; Katz et al., 2001; de Courten et al., 2002; Philipsen et al., 2002; Drage et al., 2003; Quesada-Gómez et al., 2006; Araújo et al., 2009; Dolanmaz et al., 2009), but much fewer papers have reported on these defects in archaeological contexts (Harvey and Noble, 1968; Finnegan and Marcsik, 1980; Graham, 1980; Mann, 1990; Mann and Tsaknis, 1991; Mann and Shields, 1992; Shields, 2000; Lukacs and Rodríguez Martín, 2002; Masnicová and Beňuš, 2003; Jordana et al., 2007; Vodanović et al., 2009).

In the study of Harvey and Noble (1968), a comparison between the size of the lingual defects and the radiological appearance indicated that only those cases in which resorption of the lingual cortex was extensive had the classic radiographic appearance described by Stafne. Therefore, it is possible that these lesions are present clinically in many more cases than published figures indicate, but in many instances the degree of resorption is not enough to produce radiographic changes (Sandy and Williams, 1981). If this is true, the presence of these lesions may be, as highlighted by several authors (Sandy and Williams, 1981; Apruzzese and Longoni, 1999), no more than a simple reflection of a normal anatomic 
variation in morphology, producing radiographically detectable changes only in extreme cases.

The aims of this paper are threefold: (1) to present and analyse for the first time in Portuguese osteological record prevalence data on Stafne's bone defect, (2) to analyse variations in defect prevalence between archaeological samples from a wide temporal array, and (3) to verify if more tenuous lesions in which resorption of the lingual cortex was not yet extensive had the classic radiographic appearance described by Stafne in order to validate the hypothesis that lesions are present clinically in many more cases than published figures indicate. Accurate identification of all examples of Stafne's bone defects in antiquity is thought to represent an important contribution to elucidate which factors may be responsible for this trait's cultural, ecological, temporal, and geographical patterning.

\section{MATERIALS AND METHODS}

During a study of dental pathology in 600 individuals from the three identified osteological collections of the Museum of Anthropology (Medical School, International Exchange and Identified Skeletal collections), University of Coimbra, Portugal, one of the authors (SNW) observed several cases of Stafne's defects. It was thereafter decided to extend the research of this condition to other Portuguese skeletal series from a wider temporal array, in order to document this defect through time and adequately evaluate competing hypothesis. For the purpose of this study, several human skeletal samples from the Late Neolithic (Silva, 2003), Late Roman, Medieval and Modern Portugal were, therefore, investigated by both authors (AMS and SNW). All collections on which the following observations were made are housed at the Museum of Anthropology of the University of Coimbra (MAUC), Portugal. In all, 815 mandibles were analyzed. Of these, 704 mandibles were completely preserved, 
meaning that both sides were observable. Unfortunately, the older material was not always well-preserved and some mandibles $(\mathrm{N}=111)$ were not complete because a whole segment of jaw had been broken away, preventing their full examination. The identification, date, composition, and state of preservation of the skeletal samples under study are shown is Table 1.

Sex determination of the non-identified specimens under study was made based on the morphology of the skull and hip-bone (Ferembach et al., 1980) and the morphometric analysis of the long bones (Wasterlain, 2000), the calcaneus and talus (Silva, 1995), and hip-bone (Murail et al., 2005). Sex assessment of isolated mandibles relied upon mandibular morphology, including relative overall size and robusticity, mandibular angle, shape of the gonial region and mental eminence, and width of the ascending ramus (Ferembach et al., 1980).

The age-at-death estimate of the non-identified individuals was taken from morphologic changes in the pubic symphysis and auricular surface of the ilium (Krogman and Ișcan, 1986; Lovejoy et al., 1985), as well as using the degree of closure of the cranial sutures (Masset, 1982).

The main advantage of the identified osteological collections of the Museum of Anthropology (Medical School, International Exchange, and Identified Skeletal collections) compared to the archaeological samples is the presence of known demographic parameters such as age and sex.

For the purpose of the present study, the mandibles were macroscopically examined for cortical defects, and radiographed through orthopantomography (Orthopantomograph Iberdata OP 100D; voltage: $57 \mathrm{kV}$; exposition: $3.2 \mathrm{~mA}, 17.6 \mathrm{~s}$ ).

The procedure recommended by Lukacs and Rodríguez Martín (2002) was adopted for macroscopic description of the lesions, which includes size of the defect, location of defect by 
side, position of defect on corpus, and appearance of the defect. In relation to size of the lesion, three measurements were taken: length (approximately parallel to the margin of the mandibular corpus), height (perpendicular to length), and depth (from the deepest point in the depression to a line tangent with the normal lingual cortical bone). All measurements were recorded in millimetres with needle-point calipers and periodontal graduated probes, to the nearest $0.1 \mathrm{~mm}$.

Radiological images were analysed for the presence of sharply demarcated round or oval lesions, discontinuities in the lingual cortex, or possible erosions in the buccal cortex (Vodanović et al., 2009).

Corrected prevalence of Stafne's bone defects were calculated according to Waldron (1994, 2007).

\section{RESULTS}

Given that some mandibles do not have both sides preserved for observation, it was decided to present the results separately for complete mandibles, right mandibular fragments, and left mandibular fragments. This is probably the most correct procedure because takes account of the fact that missing parts of mandibles may have had Stafne's defects. Therefore, when calculating the proportion of individuals in the study samples affected by this condition, only complete mandibles are considered.

The proportion of individuals affected by Stafne's defects by skeletal series, and sex can be seen in Table 2.

Of the 704 complete mandibles, $12(1.70 \%)$ exhibited defects on the lingual side that could be described as Stafne's defects. 
In sum, the corrected prevalence of Stafne's defects in the sample of the Late Neolithic mandibles is 5.26\% (1/19), of Middle Age specimens is 3.57\% (3/84), and of Modern individuals is $1.34 \%(8 / 595)$. No Stafne's defects were found in the mandibles from the Late Roman period, which may be due to the reduced size of the sample $(\mathrm{N}=6)$. These figures represent the percentage of individual mandibles with one or more, unilateral or bilateral, expressions of the defect present.

For all samples of mandibles, males $(2.84 \% ; 10 / 352)$ were more frequently affected than females $(0.61 \% ; 2 / 326)$.

The proportion of mandibles' fragments affected by Stafne's defects by skeletal series, and according to laterality can be seen in Table 3 . Of the 53 left mandible fragments, only one $(1.89 \%)$ exhibited a Stafne's defect. None of the 58 right mandible fragments analyzed presented lesions that could be described as Stafne's defect.

Descriptive summary of each observed lesion is presented in Table 4 (refer to Figures 1 to 4). In all, 14 defects are presented: 1 observed in one incomplete mandible and 13 found in 12 complete mandibles (one individual had bilateral lesions). Figure 1 shows the two mandibles with Stafne's defects from the Late Neolithic. In Figure 2, the three affected mandibles from the Middle Ages can be seen. Figure 3 shows seven of the eight mandibles presenting Stafne's defects from the late $19^{\text {th }}$ and early $20^{\text {th }}$ centuries. Finally, the only mandible with bilateral lesions (belonging to the identified collections) can be observed in Figure 4.

From the summary provided in Table 4, it can be seen that the most frequent shape of the defect is that of an oval. This occurred 8 times or in $57.14 \%$ of the cases. The texture of the floor of the defect showed $11(78.57 \%)$ to be rough against 3 times $(21.43 \%)$ to be smooth. 
The location of the Stafne's defect is most commonly below the third molar $(5$ cases, $35.71 \%$ ), or inferior to mylohyoid groove (3 cases, $21.43 \%)$.

With respect to sides, the defects are equally frequent on both the right and the left side. Only one of the 14 complete mandibles with Stafne's defects presented bilateral lesions. It's interesting to note, however, that those lesions are quite distinct regarding size, position on corpus, and appearance. The lesion on the left side is larger, has an oval shape, distinct margins, and is located inferior to the third molar, whereas the lesion on the right side is more tenuous, has a round shape, indistinct margins, and is situated inferior to mylohyoid groove.

Regarding radiological analysis, 8 lesions $(57.14 \%)$ could not be detected by orthopantomography. By contrast, on 6 cases (42.86\%), orthopantomographs (OPGs) revealed lesions with typical features of Stafne's defect. The lesions detected on standard radiological images were mainly the deeper defects. Lesions with measured depths inferior to $1.5 \mathrm{~mm}$ didn't have the correspondent radiographic appearance of Stafne's defects.

The OPG of mandible RB138 from Rua dos Barcos revealed a unilateral well-defined unilocular radiolucent oval lesion on the right side below the inferior alveolar canal (Figure $5)$.

OPG of the mandible 286 from International Exchange Collection (IEC) revealed a round radiolucent area on the right side at the level of third molar (Figure 6).

The OPG of the mandible 379 from IEC showed a round radiolucent area on the right side at the level of third molar (Figure 7).

OPG of mandible 643 from IEC showed an oval radiolucent area at the level of the left mandibular third molar region which revealed characteristic features of Stafne's defect (Figure 8). The more tenuous lesion on the right side of this mandible was not possible to identify on the radiological image. 
The OPG of the mandible 712 from IEC revealed a well-defined, unilocular, round radiolucent area (Figure 9). The borders exhibited dense radiopaque (sclerotic) features. The mandibular inferior border was intact.

The OPG of the mandible 1000 from IEC showed a well-defined radiolucent area on the right side at the level of third molar (Figure 10).

No pathological changes could be identified in association to any of these lesions.

\section{DISCUSSION}

Lingual cortical defects of the mandible (Stafne's defects) have often been a subject of clinical research, but there are much fewer papers reporting on these defects in archaeological contexts. Unfortunately, most anthropologists are not aware of the defects and do not include them in their analytic protocol. This situation is paradoxical, as already mentioned by Lukacs and Rodríguez Martín (2002), since human osteologists are in a privileged position to contribute to the better understanding of this trait's etiology by systematically recording it in recent, archaeological, and prehistoric skeletal collections. In fact, archaeological and museum collections present several advantages when studying Stafne's defects.

First, clinical evaluations of Stafne's defects generally require radiographic or sialographic observation and/or surgical inspection. Direct visual examination of dry mandibles, allowing prompt identification of any lesion, is a privilege of human osteologists.

Second, direct visual examination of the mandibles also facilitates differential diagnosis of any lesion observed. In the present study, all lesions were differentially diagnosed against other conditions that mimic Stafne's defects, namely odontogenic lesions, cysts and neoplasms. 
Radicular (periapical) cysts are the most common cysts of the jaws, being most frequently seen in patients between 30 and 50 years old (Scholl et al., 1999). They develop at the root apex of a non-vital tooth due to inflammatory stimulation and proliferation of the epithelial rests of Malassez (Dias et al., 2007). The cyst may displace adjacent teeth or cause mild root resorption. At radiography, they appear as round or pear-shaped, unilocular, lucent lesions in the periapical region. They are often less than $1 \mathrm{~cm}$ in diameter and are bordered by a rim of cortical bone (Scholl et al., 1999). In the lesions under study, the adjacent teeth did not present signs of severe destruction of hard dental tissues (deep carious lesions or heavy tooth abrasion) that could cause inflammation of the pulp or pulp death and lead to the destruction of periapical bone. Besides, the lamina dura was intact around the root apices and so radicular cysts could be excluded from the differential diagnosis.

The dentigerous (follicular) cyst forms within the lining of the dental follicle when fluid accumulates between the follicular epithelium and the crown of the developing or unerupted tooth (Scholl et al., 1999). Most of them manifest in adolescents and young adults and often form around the crown of an unerupted third molar. The most important features of dentigerous cyst are its ability to expand asymptomatically and its potential to displace or resorb adjacent teeth or bone. These lesions may vary in size, but when diameter exceeds 2cm, mandibular expansion may occur (Scholl et al., 1999). Radiographically, dentigerous cysts appear as well-defined, round or ovoid, corticated, lucent lesions around unerupted teeth, usually third molars. The roots of the involved tooth are frequently outside the lesion. Extremely large dentigerous cysts often develop undulating borders (Scholl et al., 1999). In the cases under study, there were no unerupted teeth adjacent to the lesions and so dentigerous cysts could be excluded from the differential diagnosis.

The odontogenic keratocysts arise from the dental lamina and other sources of odontogenic epithelium. Most of them are found during the $2^{\text {nd }}$ to $4^{\text {th }}$ decades of life, although 
they can occur at any age. Although they are commonly seen in the posterior mandible (ramus and body), odontogenic keratocysts may also occur in the anterior mandible or anywhere in the maxilla (Scholl et al., 1999). Radiographically, an odontogenic keratocyst usually appears as a unilocular, lucent lesion with smooth, corticated borders that is often associated with an impacted tooth. They are more likely to show aggressive growth than other odontogenic cysts and may have undulating borders and a multilocular appearance. Besides, odontogenic keratocysts may cause cortical thinning, tooth displacement, and root resorption (Scholl et al., 1999). Considering that none of these features was observed in the present cases, the diagnosis of odontogenic keratocyst was discarded.

A traumatic bone cyst (also referred to as haemorrhagic bone cyst) is not a true cyst because it lacks an epithelial lining. Its cause is unknown, although some believe that it develops after trauma. Most lesions are found during the $2^{\text {nd }}$ decade of life on routine radiological examination and their most common location is the mandible (Scholl et al., 1999; Vodanović et al., 2009). The traumatic bone cyst can have similar radiographic features to that of an odontogenic cyst and also tends to appear between the roots of the teeth (CortellBallester et al., 2009). It appears as a radiolucent image with irregular or scalloped but well defined margins. The size is variable and a fine sclerotic margin is sometimes observable (Cortell-Ballester et al., 2009). When the radiolucency affects the interdental bone spaces, the lesion appears lobular or scalloped. Root resorption is rare, and can cause disappearance of the hard lamina. These morphology and radiological appearances are distinct from those presented here, being traumatic bone cyst therefore excluded.

Central giant cell granuloma is a relatively common lesion of the jaw, affecting the mandible twice as frequently as the maxilla. These lesions typically occur in adolescents and young adults (Scholl et al., 1999). The central giant cell granuloma is more commonly found anterior to the lower first molar where deciduous teeth are found and often causes marked 
expansion of the bone, displacement of teeth and resorption of the lamina dura (Cohen and Hertzanu, 1988), features not seen in these cases.

Ameloblastomas are benign epithelial neoplasms, representing around $10 \%$ of odontogenic tumours. They typically manifest in the $3^{\text {rd }}$ to $5^{\text {rd }}$ decades of life but have also been reported in younger or older individuals. Around $80 \%$ of the ameloblastomas occur in the ramus and posterior body of the mandible. These neoplasms develop from various sources of odontogenic epithelium, including dental follicular lining epithelium. The ameloblastoma exhibit locally aggressive behaviour and is often an expansible lesion that causes resorption and displacement of the adjacent teeth (Scholl et al., 1999). Radiographically, ameloblastomas may appear as well-defined, unilocular, well-corticated, lucent lesions that are often associated with the crowns of impacted or unerupted teeth. Others are multilocular with internal septa and a honey-comb or soap bubble appearance (Scholl et al., 1999). These morphology and radiological appearances are distinct from those presented here, being the diagnosis of ameloblastoma therefore excluded.

In sum, the 14 Stafne's defects analyzed in this study exhibit a typical appearance, leaving no doubts about the diagnosis. A key anatomic feature of Stafne bone defect is that the mandibular concavity is always open on its lingual face and the mandibular bone cortical is not compromised (Araújo et al., 2009). The presence of a lingual opening surrounded by perfectly sound cortical bone excludes the majority of differential diagnoses that one may consider.

Another advantage of the osteological material is that variations in defect prevalence between archaeological samples from a wide temporal range may be investigated. In the present study, the prevalence of Stafne's defects was investigated for several Portuguese skeletal samples dated from the Late Neolithic to the Modern period. The prevalence of Stafne's defects in the global sample analyzed in this study is $1.70 \%(12 / 704)$. The proportion 
of individuals affected by Stafne's defects is 5.26\% (1/19) for the Late Neolithic, $0 \%(0 / 6)$ for the Late Roman, 3.57\% (3/84) for the Middle Ages, and 1.34\% (8/595) for the Modern period. The lower prevalence recorded in the Late Roman sample may probably be due to its small sample size. These results are in close agreement with the results obtained by other authors for samples from distinct temporal and geographical origin (Table 5). Finnegan and Marcsik (1980) examined 5519 mandibles from several archaeological sites in Hungary and found $59(1.07 \%)$ Stafne bone defects. For the Avar period sample from Hungary, however, Finnegan and Marcsik (1981) reported a higher prevalence of 3.39\%. Shields (2000) analysed 7686 mandibles sampled globally within the past 2000 years and concluded that the prevalence of Stafne's bone defects ranges from $10 \%$ in the tropics to virtually $0 \%$ in most of the arctic. Lukacs and Rodríguez Martín (2002) studied the lingual cortical defects of the mandibular corpus in 452 prehistoric skeletons of Tenerife (Canary Islands, Spain). The prevalence of Stafne's defects in their sample was 3.32\%. Masnicová and Beňuš (2003) found that among the skeletal remains from the Great Moravia and Middle Ages Cemeteries at Devin (Slovakia), the prevalence of Stafne's defects was 1.2\%. More recently, Vodanović et al. (2009) analyzed the prevalence of Stafne's defects in a large composite Croatian archaeological series and found that 4250 mandibles produced $2(0.05 \%)$ Stafne's defects. Different prevalences reported in the anthropological literature suggest some population variation in defect frequency, as already noted by Vodanović et al. (2009).

According to the literature, this defect most frequently displays an ovoid shape, rough floor, showing no clear side preference. Besides, it primarily affects middle-aged or older individuals and is more prevalent in males than females (Katz et al., 2001; Lukacs and Rodríguez Martín, 2002; Masnicová and Beňuš, 2003; Vodanović et al., 2009). All these tendencies were confirmed in the analysed samples: the highest frequency was found in the fifth, sixth and seventh decades of life; a striking male predilection was found, with more than 
$70 \%$ of the cases occurring in men; the most frequent shape of the defects was that of an oval (57.14\%), and the texture of their floor showed to be rough more often $(78.57 \%)$. With respect to sides, the defects were equally frequent on both the right and the left side, as expected.

Finally, data on Stafne's bone defects prevalence in living populations can be influenced by different diagnostic techniques, but investigations performed on dry mandibles are not affected by this problem (Vodanović et al., 2009). As explained by Vodanović et al. (2009), the nature of the development and growth of Stafne's defects is opposite to that of the periapical lesions. This later lesion starts to develop close to the tooth root in the middle of the jaw and expand to the outer border of the bone. Depending on the severity of the inflammatory process, the bone defect caused by odontogenic infection does not necessarily have to be visible on the outer border of the jaw. That is the reason why radiographic methods are considered the most accurate way of determining the prevalence of periapical lesions. If they are not used in dry skulls, false low prevalence rates can be established. In opposition, Stafne's defects are thought to start at the outer border of the bone and expand inwards. If this is true, it means that every phase of its development is easily and unmistakable identified in dry bone (Vodanović et al., 2009). On the other hand, it is possible that Stafne's defects produce radiographically detectable changes only in extreme cases (Apruzzese and Longoni, 1999). If this is the case, more tenuous lesions, in which resorption of the lingual cortex was not yet extensive, may be promptly identified only in osteological material. In fact, in the present study, 8 lesions $(57.14 \%$ ) could not be detected by orthopantomography, suggesting that the incidence of about $0.10-0.48 \%$ of lingual mandibular bone depressions reported for the living populations is probably an underestimation. Besides, the present analysis suggests that Stafne's defects are detected by $x$-rays only when their depth is $\geq 1.5 \mathrm{~mm}$, but more data regarding mandibular defects are required to provide a reliable test. 


\section{CONCLUSION}

In view of the scarcity with which Stafne's defects have been diagnosed in archaeological specimens in general, and considering the temporal and regional differences emerging in the frequencies of these defects, it is important to report all new cases which are discovered. Besides, as already highlighted by Lukacs and Rodríguez Martín (2002), accurate identification of all examples of Stafne's bone defects in antiquity is thought to represent an important contribution to elucidate which factors may be responsible for this trait's cultural, ecological, temporal, and geographical patterning. The present study is the first to report several cases of Stafne's defects in Portuguese human skeletal remains from distinct time periods, and adds to the very few osteoarchaeological case descriptions available for this condition. For these reasons, it is believed that data presented in this study are of not only anthropological but also clinical relevance. Besides, we venture to suggest that the mandible PM12272 from the Tholos de Paimogo I site (4250 \pm 90 BP; Sac- 1556) may be the oldest known case of Stafne's defect until now.

\section{ACKNOWLEDGMENTS}

The authors would like to thank Câmara Municipal de Santarém, Museu Municipal Leonel Trindade de Torres Vedras, Museu Arqueológico de São Miguel de Odrinhas, and Centro de Investigação em Antropologia e Saúde. The authors are grateful to the Museum of Anthropology of the University of Coimbra for permission to study the identified osteological collections. The authors also acknowledge the Clínica Universitária de Imagiologia dos Hospitais da Universidade de Coimbra for producing the radiographs of the mandibles. 
Finally, the authors would like to thank the editor of the journal and the anonymous reviewers whose valuable comments and suggestions allowed us to improve the manuscript.

\section{LITERATURE CITED}

Apruzzese D, and Longoni S. 1999. Stafne cyst in an anterior location. J Oral Maxillofac Surg 57: 333-338.

Araújo F, Marques T, Correia A, Silva A, and Tinoco J. 2009. Differential diagnosis of a salivary gland bone defect by means of computerized tomography: a case report. Rev Odonto Ciênc 24: 218-220.

Ariji E, Fujiwara N, Tabata O, Nakayama E, Kanda S, Shiratsuchi Y, Oka M. 1993. Stafne's bone cavity: classification based on outline and content determined by computer tomography. Oral Surg Oral Med Oral Pathol 76: 375-380.

Barker GR. 1988. A radiolucency of the ascending ramus of the mandible associated with invested parotid salivary gland material and analogous with a Stafne bone cavity. Br J Oral Maxillofac Surg 26: 81-84. DOI: 10.1016/0266-4356(88)90155-6

Branstetter BF, Weissman JL, and Kaplan SB. 1999. Imaging of a Stafne bone cavity: what MR adds and why a new name is needed. Am J Neuroradiol 20: 587-589.

Buchner A, Carpenter WM, Merrell PW, and Leider AS. 1991. Anterior lingual mandibular salivary gland defect: evaluation of twenty-four cases. Oral Surg Oral Med Oral Pathol 71: 131-136. DOI: 10.1016/0030-4220(91)90452-I

Cohen MA, and Hertzanu Y. 1988. Radiologic features, including those seen with computed tomography, of central giant cell granuloma of the jaws. Oral Surg Oral Med Oral Pathol 65: 255-261. 
Correll RW, Jensen JL, and Rhyne RR. 1980. Lingual cortical mandibular defects. Oral Surg 50: 287-291.

Cortell-Ballester I, Figueiredo R, Berini-Aytés L, and Gay-Escoda C. 2009. Traumatic bone cyst: a retrospective study of 21 cases. Med Oral Patol Oral Cir Bucal 14: E239-E243.

Cunha E, and Wasterlain S. 2007. The Coimbra identified osteological collections. In: Grupe G, Peters J, editors. Skeletal series and their socio-economic context. Documenta Archaeobiologiae, vol. 5. Rahden/Westf: Verlag Marie Leidorf GmbH. p 2333.

de Courten A, Küffer R, Samson J, and Lombardi T. 2002. Anterior lingual mandibular salivary gland defect (Stafne defect) presenting as a residual cyst. Oral Surg Oral Med Oral Pathol Oral Radiol Endod 94: 460-464. DOI: 10.1067/moe.2002.125196

Dias GJ, Prasad K, Santos AL. 2007. Pathogenesis of apical periodontal cysts: guidelines for diagnosis in paleopathology. Int J Osteoarchaeol 17: 619-626. DOI: 10.1002/oa.902

Dolanmaz D, Etöz OA, Pampu AA, Kiliç E, and Șișman Y. 2009. Diagnosis of Stafne's bone cavity with dental computerized tomography. Eur J Gen Med 6: 42-45.

Drage NA, Renton T, and Odell EW. 2003. Atypical Stafne bone cavity. Clinical Radiology Extra 58: 51-53. DOI: 10.1016/S1477-6804(03)00011-6

Ferembach D, Schwidetzky I, Stloukal M. 1980. Recommendations for age and sex diagnosis of skeletons. J Hum Evol 9: 517-550.

Finnegan M, and Marcsik A. 1980. Anomaly or pathology: the Stafne defect as seen in archaeological material and modern clinical practice. J Hum Evol 9: 19-31.

Finnegan M, and Marcsik A. 1981. The description and incidence of the Stafne idiopathic bone defect in six Avar period populations. Acta Biologica Szeged 27: 215-221. 
Graham EE. 1980. A probable submandibular gland defect in a prehistoric mandible. Oral Surg Oral Med Oral Pathol Oral Radiol Endod 50: 187-189.

Harvey W, and Noble HW. 1968. Defects on the lingual surface of the mandible near the angle. The British Journal of Oral Surgery 6: 75-83.

Hayashi Y, Kimura Y, and Nagumo M. 1984. Anterior lingual mandibular bone concavity: report of a case. Oral Surg Oral Med Oral Pathol 57: 139-142.

Jordana X, García Sívoli C, Galtés I, Palacios M, Cos M, and Malgosa A. 2007. Report on a Stafne defect in a man from Medieval age. J Oral Maxillofac Surg 65: 556559. DOI: $10.1016 /$ j.joms.2005.07.023

Karmiol M, and Walsh RF. 1968. Incidence of static bone defect of the mandible. Oral Surg 26: 225-228.

Katz J, Chaushu G, and Rotstein I. 2001. Stafne's bone cavity in the anterior mandible: a possible diagnostic challenge. Journal of Endodontics 27: 304-307.

Krogman WM, and IșcanYM. 1986. The human skeleton in forensic medicine. Springfield: CC Thomas.

Lovejoy C, Meindl R, Pryzbeck T, Mensforth R. 1985. Chronological metamorphosis of the auricular surface of the ilium: a new method for the determination of adult skeletal age at death. Am J Phys Anthropol 68: 15-28.

Lukacs JR, and Rodríguez Martín C. 2002. Lingual cortical mandibular defects (Stafne's defect): an anthropological approach based on Prehistoric skeletons from the Canary Islands. Int J Osteoarchaeol 12: 112-126. DOI: 10.1002/oa.592

Mann RW. 1990. Incipient lingual cortical mandibular defect in a 10- to 12-year-old American Indian child. Am J Roentgenol 154: 658-659. 
Mann RW, and Shields ED. 1992. Cavitation defects on the lingual ramus: a further expression of Stafne's defect. Journal of Craniofacial Genetics and Developmental Biology 12: $167-173$.

Mann RW, and Tsaknis PJ. 1991. Cortical defects in the mandibular sulcus. Oral Surg Oral Med Oral Pathol 71: 514-516.

Masnicová S, and Beňuš R. 2003. Developmental anomalies in skeletal remains from the Great Moravia and Middle ages cemeteries at Devín (Slovakia). Int J Osteoarchaeol 13: 266-274. DOI: 10.1002/oa.684

Masset C. 1982. Estimation de l'âge au décès par les sutures crâniennes. Thèse de Doctorat. Paris: Université Paris VII.

Murail P, Bruzek J, Houët F, Cunha E. 2005. Dsp: a tool for probabilistic sex diagnosis using worldwide variability in hip-bone measurements. Bulletins et Mémoires de la Société d'Anthropologie de Paris, n.s., 17 (3-4): 167-176.

Oikarinen VJ, and Julku M. 1974. An orthopantomographic study of developmental mandibular bone defects. Int J Oral Surg 3: 71-76.

Philipsen H, Takata T, Reichart P, Sato S, and Suei Y. 2002. Lingual and buccal mandibular bone depressions: a review based on 583 cases from a world-wide literature survey, including 69 new cases from Japan. Dentomaxillofac Radiol 31: 281-290.

Queiroz LM, Rocha RS, de Medeiros, KB, da Silveira EJ, and Lins RD. 2004. Anterior bilateral presentation of Stafne defect: An unusual case report. J Oral Maxillofac Surg 62: 613-615. DOI: 10.1016/j.joms.2003.04.019

Quesada-Gómez C, Castellón E V, Aytés LB, and Escoda CG. 2006. Stafne bone cavity: a retrospective study of 11 cases. Med Oral Patol Oral Cir Bucal 11: E277-E280.

Regezi JA, Sciubba JJ, and Pogrel MA. 2000. Atlas of oral and maxillofacial pathology. Philadelphia: W. B. Saunders Company. 
Sandy JR, and Williams DM. 1981. Anterior salivary gland inclusion in the mandible: pathological entity or anatomical variant? Br J Oral Surg 19: 223-229.

Scholl RJ, Kellett HM, Neumann DP, Lurie AG. 1999. Cysts and cystic lesions of the mandible: clinical and radiologic-histopathologic review. RadioGraphics 19: 11071124.

Segev Y, Puterman M, Bodner L. 2006. Stafne bone cavity - magnetic resonance imaging. Med Oral Patol Oral Cir Bucal 11: E345-E347.

Shafer WG, Hine MK, and Levy BM. 1983. A textbook of oral pathology. Philadelphia: W. B. Saunders Company.

Shibata H, Yoshizawa N, and Shibata T. 1991. Developmental lingual defect of the mandible: report of a case. Int J Oral Maxillofac Surg 20: 328-329. DOI: 10.1016/S09015027(05)80259-0

Shields ED. 2000. Technical note: Stafne static mandibular bone defect - further expression on the buccal aspect of the ramus. Am J Phys Anthropol 111: 425-427.

Silva AM. 1995. Sex assessment using calcaneus and talus. Antropologia Portuguesa 13: 85-97.

Silva AM. 2003. Portuguese Populations of the Late Neolithic and Chalcolithic Periods exhumed from Collective burials: an overview. Anthropologie XLI/1-2: 55 - 64.

Soames JV, and Southam JC. 2005. Oral pathology. Oxford: Oxford University Press.

Stafne EC. 1942. Bone cavities situated near the angle of the mandible. J Am Dent Assoc 29: 1969-1972.

Vodanović M, Šlaus M, Galić I, Marotti M, and Brkić H. 2009. Stafne's defects in two mandibles from archaeological sites in Croatia. Int J Osteoarchaeol. DOI: 10.1002/oa.1101 (in press). 
Waldron T. 1994. Counting the dead: the epidemiology of skeletal populations.

Chichester: John Wiley \& Sons.

Waldron T. 2007. Palaeoepidemiology: the measure of disease in the human past.

Walnut Creek, CA: Left Coast Press.

Wasterlain SN. 2000. Morphé: análise das proporções entre os membros, dimorfismo sexual e estatura de uma amostra da Colecção de Esqueletos Identificados do Museu Antropológico da Universidade de Coimbra. Masters Dissertation on Human Evolution. Coimbra: University of Coimbra.

Whaites E. 2007. Dental radiography and radiology. $4^{\text {th }}$ edn. Edinburgh: Churchill Livingstone Elsevier. 
Table 1. Identification, date, composition, and state of preservation of the Portuguese skeletal samples under study.

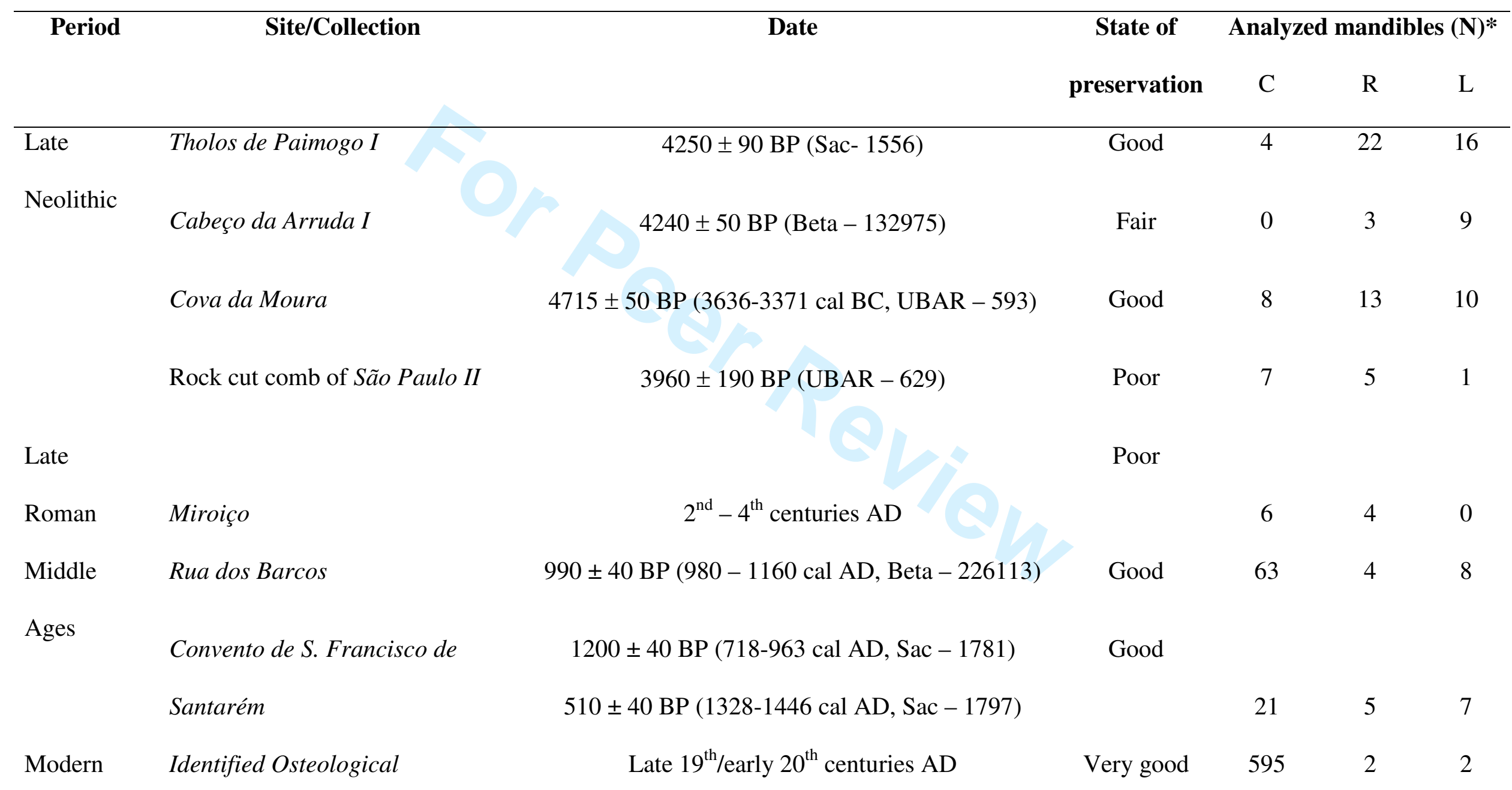




\section{Collections}

Total

704

58

53

$* \mathrm{C}=$ Complete; $\mathrm{R}=$ Only the right side of the mandible could be analyzed; $\mathrm{L}=$ Only the left side of the mandible could be analyzed. 
Table 2. Proportion of individuals affected by Stafne's defects by skeletal series, and sex.

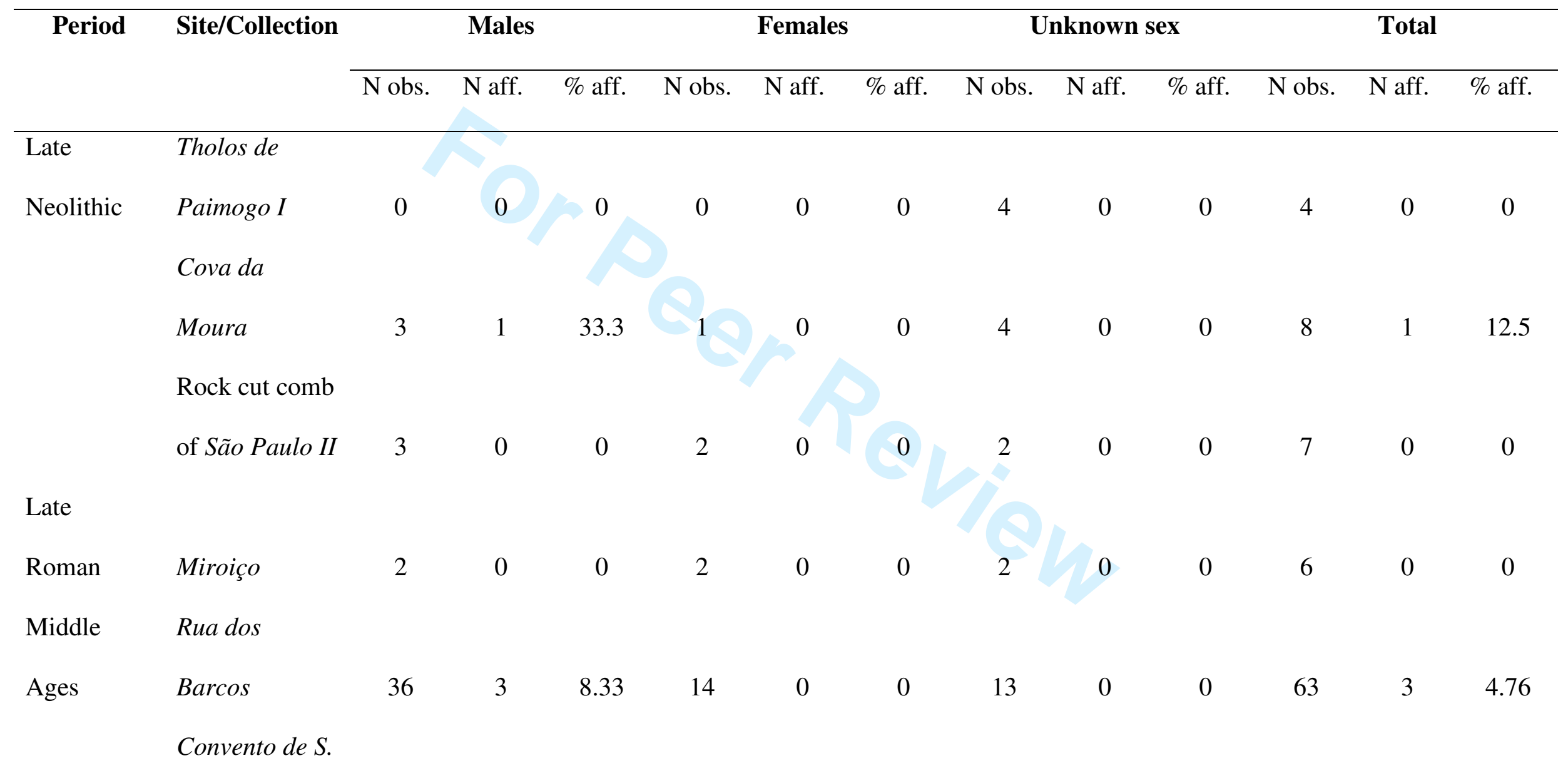


Francisco de

Santarém

12
0

0

8

0

$0 \quad 1$

0

0

21

0

\begin{tabular}{|c|c|c|c|c|c|c|c|c|c|c|c|c|c|}
\hline Modern & \multicolumn{13}{|l|}{ Identified } \\
\hline Total & & 352 & 10 & 2.84 & 326 & 2 & 0.61 & 26 & 0 & 0 & 704 & 12 & 1.70 \\
\hline
\end{tabular}


Table 3. Proportion of mandibles' fragments affected by Stafne's defects according to laterality.

\begin{tabular}{|c|c|c|c|c|c|c|c|c|c|c|}
\hline \multirow[t]{2}{*}{ Period } & \multirow[t]{2}{*}{ Site/Collection } & \multicolumn{3}{|c|}{ Right Fragments } & \multicolumn{3}{|c|}{ Left Fragments } & \multicolumn{3}{|c|}{ Total } \\
\hline & & N obs. & $\mathrm{N}$ aff. & $\%$ aff. & N obs. & $\mathrm{N}$ aff. & $\%$ aff. & N obs. & $\mathrm{N}$ aff. & $\%$ aff. \\
\hline Neolithic/ & Tholos de & & 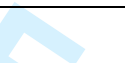 & & & & & & & \\
\hline \multirow[t]{6}{*}{ Chalcolithic } & $\begin{array}{l}\text { Paimogo I } \\
\text { Cabeço da }\end{array}$ & 22 & 0 & 0 & 16 & 1 & 6.25 & 38 & 1 & 2.6 \\
\hline & Arruda I & 3 & 0 & 0 & 9 & 0 & 0 & 12 & 0 & 0 \\
\hline & Cova da & & & & & & & & & \\
\hline & Moura & 13 & 0 & 0 & 10 & 0 & 0 & 23 & 0 & 0 \\
\hline & Rock cut comb & & & & & & & & & \\
\hline & of São Paulo II & 5 & 0 & 0 & 1 & 0 & 0 & 6 & 0 & 0 \\
\hline \multicolumn{11}{|l|}{ Late } \\
\hline Roman & Miroiço & 4 & 0 & 0 & 0 & 0 & 0 & 4 & 0 & 0 \\
\hline Middle & Rua dos & & & & & & & & & \\
\hline Ages & Barcos & 4 & 0 & 0 & 8 & 0 & 0 & 12 & 0 & 0 \\
\hline
\end{tabular}


Convento de $S$.

Francisco de 5

0

7

$0 \quad 0$

12

0

Santarém

Modern Identified

Osteological

Collections

$\begin{array}{llll}2 & 0 & 0 & \\ 58 & 0 & 0 & 53\end{array}$

Total

20 
Table 4. Descriptive summary of each observed Stafne's defect.

\begin{tabular}{|c|c|c|c|c|c|c|c|c|c|c|c|}
\hline Site & $\begin{array}{l}\text { Spec. } \\
\text { Nr. }\end{array}$ & $\begin{array}{l}\text { Sex/Age } \\
\text { (years) }\end{array}$ & $\begin{array}{c}\text { State of } \\
\text { Completeness* }\end{array}$ & Side & Length & Height & Depth & Texture & Position $\ddagger$ & Margins & Shape \\
\hline \multicolumn{12}{|l|}{ Tholos de } \\
\hline Paimogo I & 12272 & ?/adult & I & $\mathrm{L}$ & 5.1 & 4.1 & 1.0 & rough & IMHG & Y & round \\
\hline \multicolumn{12}{|l|}{ Cova da } \\
\hline Rua dos & 10 & $\mathrm{M} / 30-40$ & $\mathrm{C}$ & $\mathrm{L}$ & 3.7 & 2.6 & 1.0 & rough & PMHG & Y & round \\
\hline \multirow[t]{2}{*}{ Barcos } & 36 & $\mathrm{M} / 50+$ & $\mathrm{C}$ & $\mathrm{L}$ & 6.1 & 4.6 & 0.5 & rough & IM1M2 & $\mathrm{N}$ & oval \\
\hline & 138 & $\mathrm{M} / 45 \pm 14.76$ & $\mathrm{C}$ & $\mathrm{R}$ & 10.5 & 6.7 & 8.0 & rough & IMHG & Y & oval \\
\hline \multirow[t]{3}{*}{ collection } & 379 & $\mathrm{~F} / 65$ & $\mathrm{C}$ & $\mathrm{R}$ & 5.4 & 4.6 & 1.5 & smooth & IM3 & $\mathrm{N}$ & round \\
\hline & 643 & $\mathrm{M} / 78$ & $\mathrm{C}$ & B & $\mathrm{L}-6.1$ & $L-2.4$ & $\mathrm{~L}-4.5$ & L- rough & $\mathrm{L}-\mathrm{IM} 3$ & $L-Y$ & L - oval \\
\hline & & & & & $\mathrm{R}-4.9$ & $\mathrm{R}-3.1$ & $\mathrm{R}-1.0$ & $\mathrm{R}$ - rough & R - IMHG & $\mathrm{R}-\mathrm{N}$ & $\mathrm{R}$ - round \\
\hline
\end{tabular}




\begin{tabular}{|c|c|c|c|c|c|c|c|c|c|c|c|}
\hline & 712 & $\mathrm{M} / 56$ & $\mathrm{C}$ & $\mathrm{L}$ & 4.4 & 3.9 & 3.0 & rough & IM2 & $\mathrm{Y}$ & round \\
\hline & 1000 & $\mathrm{M} / 39$ & $\mathrm{C}$ & $\mathrm{R}$ & 6.6 & 4.4 & 2.5 & smooth & IM3 & $\mathrm{Y}$ & oval \\
\hline Skeletal & 194 & $\mathrm{~F} / 65$ & $\mathrm{C}$ & $\mathrm{L}$ & 6.7 & 4.4 & 0.5 & rough & PMHG & $\mathrm{N}$ & oval \\
\hline collection & 455 & $\mathrm{M} / 63$ & $\mathrm{C}$ & $\mathrm{L}$ & 5.1 & 3.0 & 0.5 & rough & IM3 & $\mathrm{N}$ & oval \\
\hline
\end{tabular}

* I = Incomplete mandible; $\mathrm{C}=$ Complete mandible.

$\ddagger \mathrm{IMHG}=$ inferior to mylohyoid groove; $\mathrm{PMHG}=$ posterior to mylohyoid groove; IM3 = inferior to M3; IM2 = inferior to $\mathrm{M} 2$; IM1M2 = the defect extends from beneath the distal margin of M1 to the mesial aspect of M2; M1= inferior to M1. 
Table 5. Data on investigations of Stafne's defects in archaeological populations.

\begin{tabular}{|c|c|c|c|c|}
\hline Author(s), year of publication & $\begin{array}{c}\text { Geographic location } \\
\text { of the sample }\end{array}$ & Sample size & $\begin{array}{l}\text { Examination } \\
\text { technique* }\end{array}$ & $\begin{array}{c}\text { Prevalence } \\
\text { (\%) }\end{array}$ \\
\hline Finnegan and Marcsik, 1981 & Avar period & 295 & M & 3.39 \\
\hline Shields, 2000 & Sampled globally within the past 2000 years & 7686 & M & $0-10.0$ \\
\hline Masnicová and Beňuš, 2003 & $9^{\text {th }}: 11^{\text {th }}-12^{\text {th }}$ & 124 & M & 1.2 \\
\hline Vodanović et al., 2009 & $\begin{array}{c}\text { Approximately } 8000 \mathrm{BC} \text { to } 18^{\text {th }} \\
\text { century AD }\end{array}$ & 4250 & $\mathrm{M}, \mathrm{CT}$ & 0.05 \\
\hline
\end{tabular}




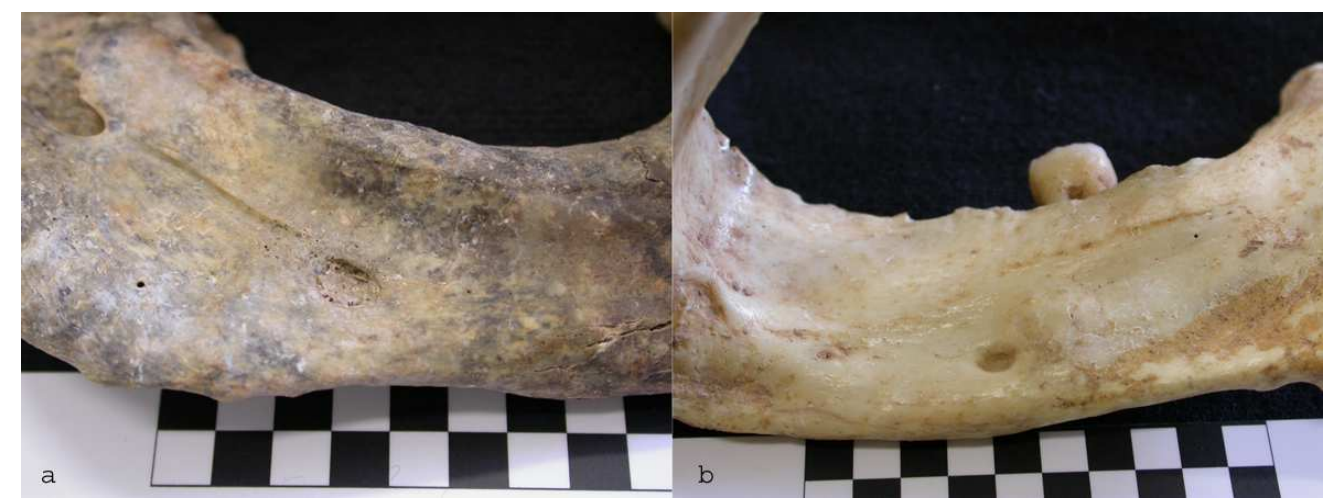

Figure 1. Expression of Stafne's defect in two Late Neolithic specimens, Portugal. a, Tholos de Paimogo I - 12272, adult, unknown sex; b, Cova da Moura - 3, adult, male. $99 \times 37 \mathrm{~mm}(300 \times 300 \mathrm{DPI})$ 
Figure 2. Expression of Stafne's defect on the specimens from Middle Ages, Portugal. a, Rua dos Barcos - 10, 30-40 years-old, male; b, Rua dos Barcos - 36, +50 years-old, male; c, Rua dos Barcos - 138, 45 \pm 14.76 years-old, male. $150 \times 37 \mathrm{~mm}(300 \times 300 \mathrm{DPI})$ 

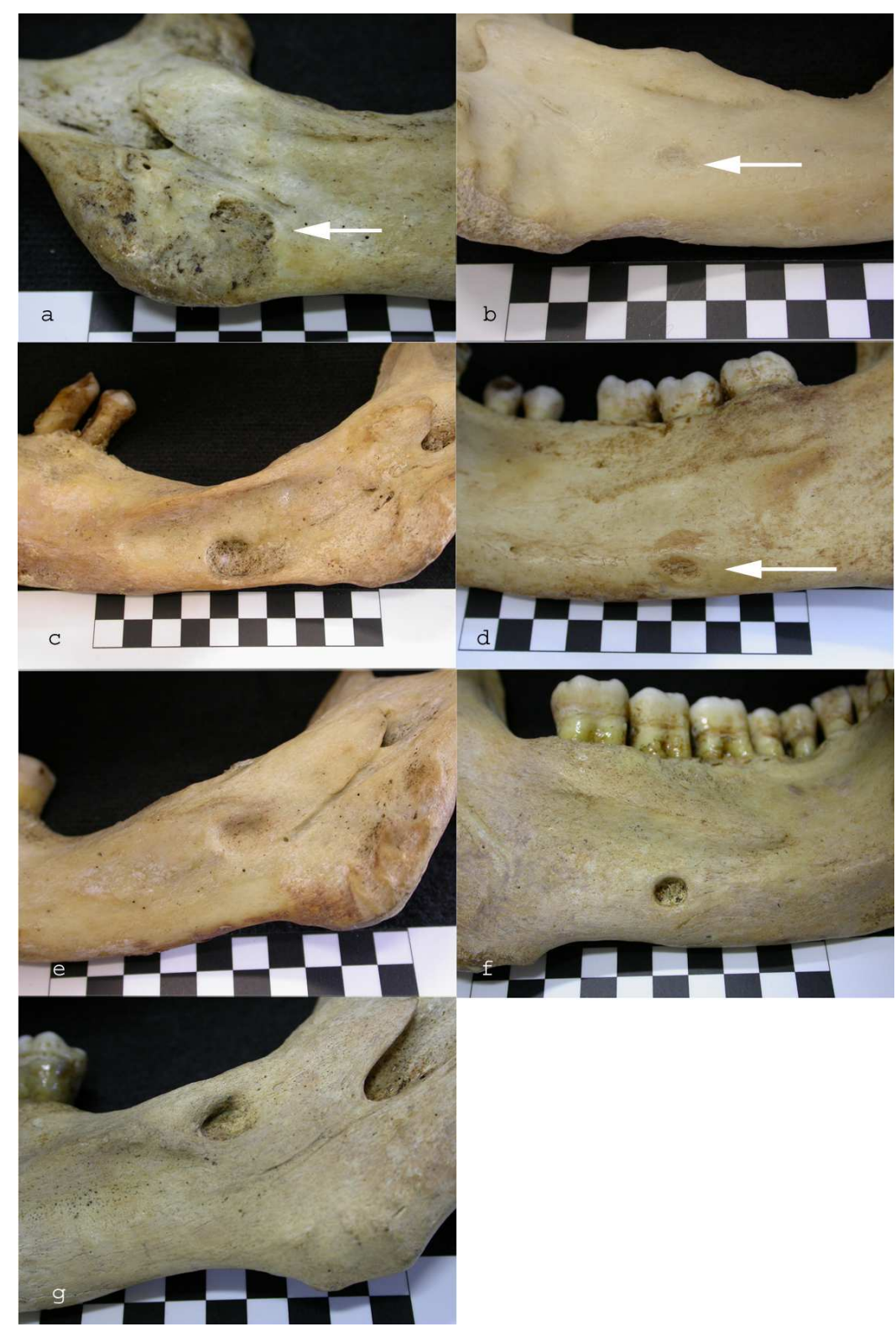

Figure 3. Expression of Stafne's defect in seven mandibles from the late 19th and early 20th centuries, Portugal. a, Skeletal collection - 194, 65 years-old, female; b, Skeletal collection - 455, 63 years-old, male; c, International Exchange collection - 286, 74 years-old, male; d, International Exchange collection - 309, 23 years-old, male; e, International Exchange collection - 379, 65 years-old, female; f, International Exchange collection - 712, 56 years-old, male; g, International Exchange collection - 1000, 39 years-old. $99 \times 149 \mathrm{~mm}(300 \times 300 \mathrm{DPI})$ 

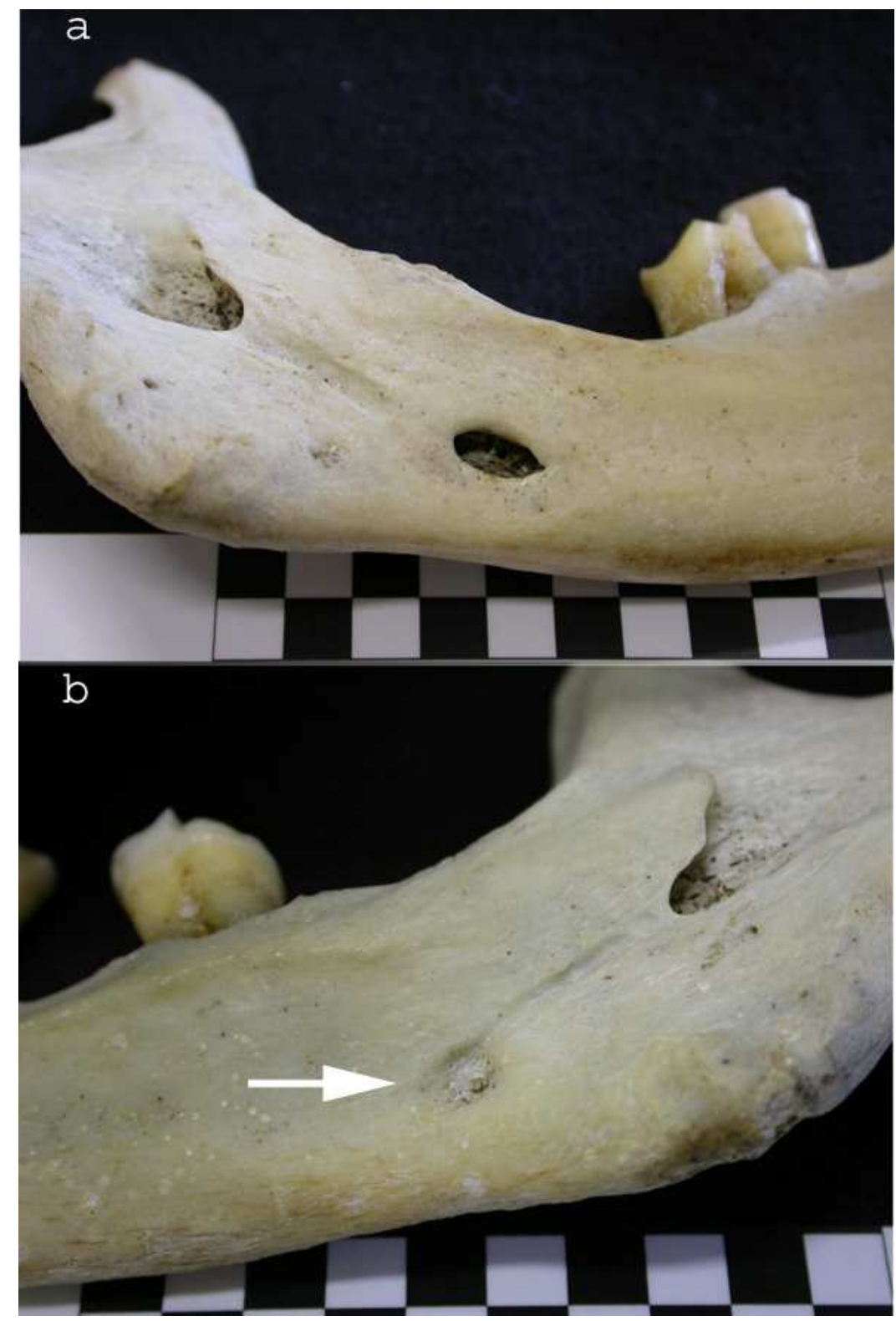

Figure 4. Bilateral expression of Stafne's defect in one mandible from the late 19th and early 20th centuries, Portugal. a, left side; b, right side. [International Exchange collection - 643, 78 yearsold, male]. $50 \times 74 \mathrm{~mm}(300 \times 300$ DPI $)$ 


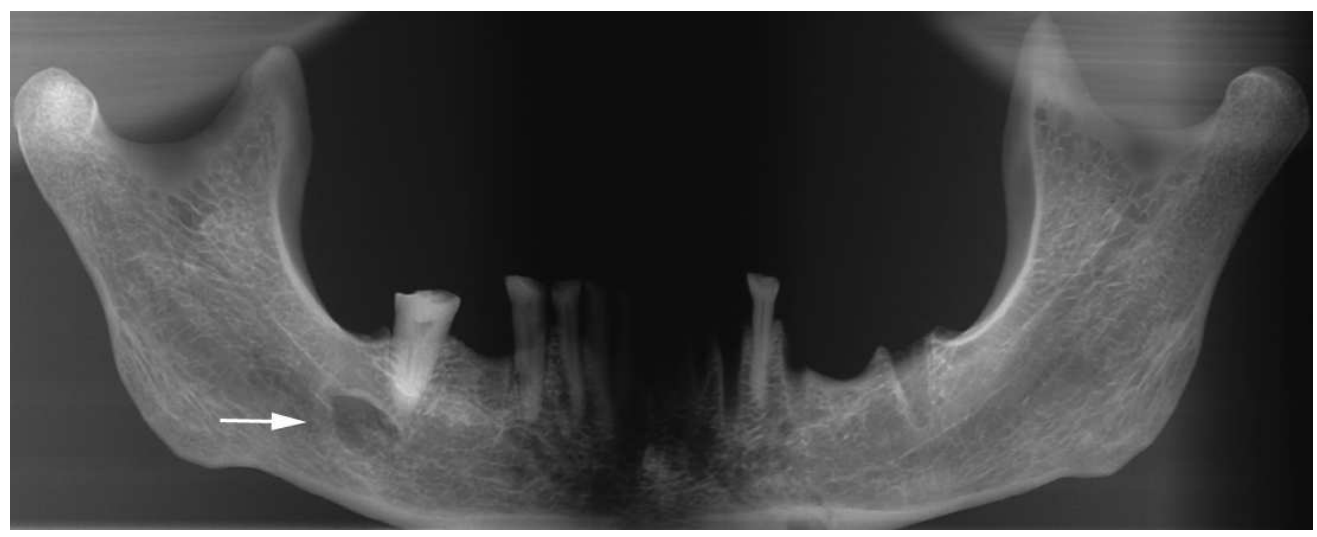

Figure 5. Orthopantomograph of mandible 138 from Rua dos Barcos, revealing a unilateral welldefined unilocular radiolucent oval lesion on the right side below the inferior alveolar canal. $93 \times 37 \mathrm{~mm}(300 \times 300 \mathrm{DPI})$ 
Figure 6. OPG of the mandible 286 from International Exchange Collection, where it can be observed a round radiolucent area on the right side at the level of third molar. $140 \times 53 \mathrm{~mm}(300 \times 300$ DPI $)$ 


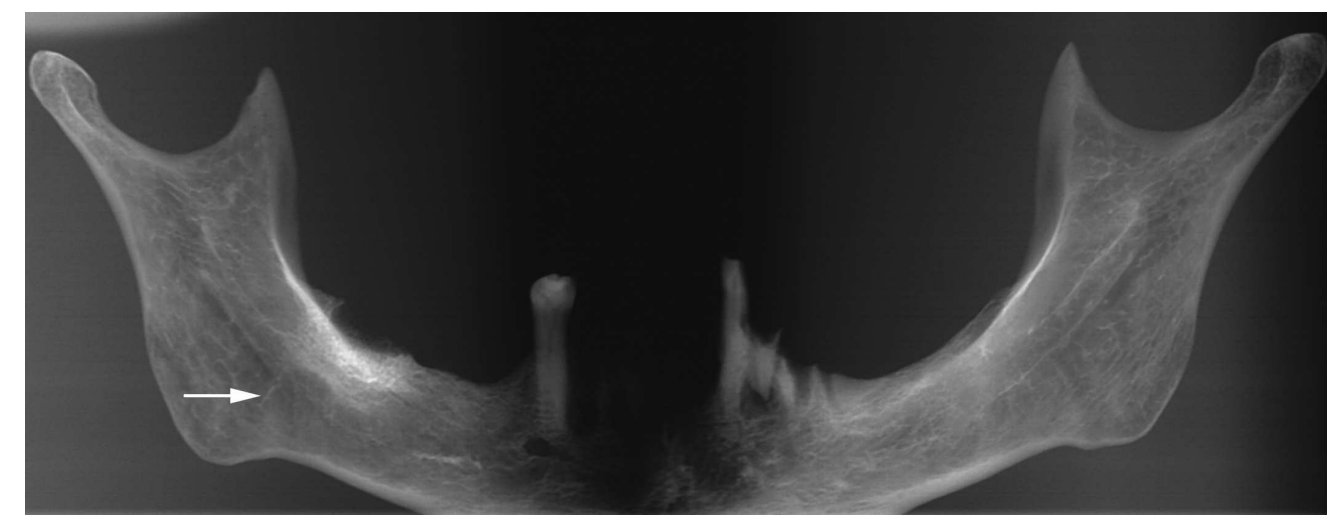

Figure 7. OPG of the mandible 379 from International Exchange Collection. Note the round radiolucent area on the right side at the level of third molar. $179 \times 69 \mathrm{~mm}(300 \times 300 \mathrm{DPI})$ 


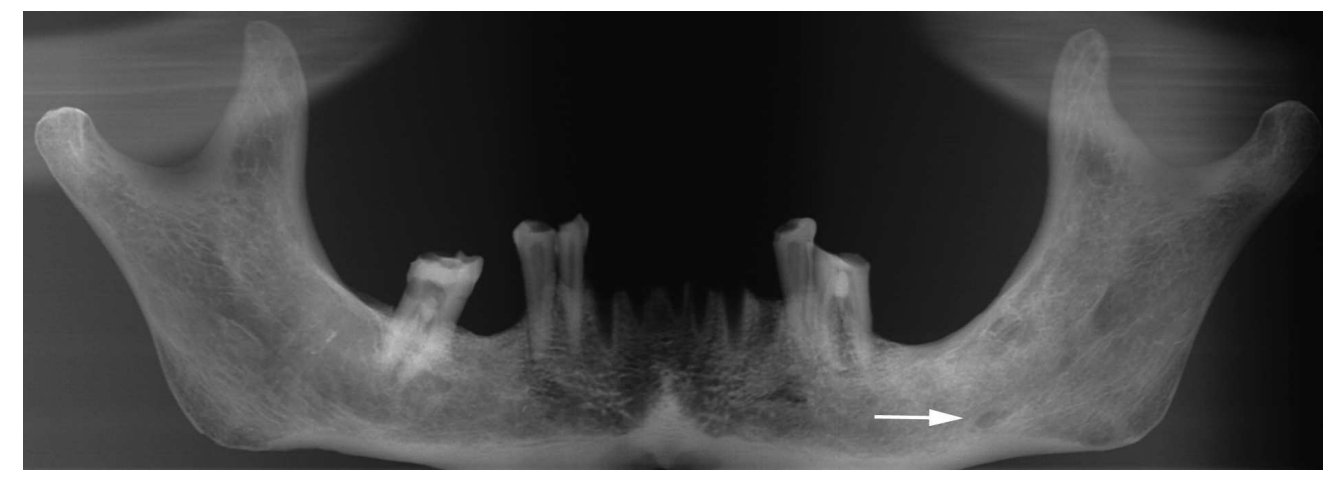

Figure 8. OPG of mandible 643 from International Exchange Collection. Note the lingual oval radiolucent area at the level of the left mandibular third molar region. The more tenuous lesion on the right side of this mandible was not possible to identify on this radiological image. $160 \times 56 \mathrm{~mm}(300 \times 300 \mathrm{DPI})$ 
Figure 9. OPG of the mandible 712 from International Exchange Collection, where it can be seen a well-defined, unilocular, round radiolucent area. Note the dense radiopaque (sclerotic) features of the borders.

$154 \times 63 \mathrm{~mm}(300 \times 300 \mathrm{DPI})$ 
Figure 10. OPG of the mandible 1000 from International Exchange Collection, showing a welldefined radiolucent area on the right side at the level of third molar. $107 \times 31 \mathrm{~mm}(300 \times 300 \mathrm{DPI})$ 